PanAfrican
ogoOMedical
808Journal

Case report, Volume 5, issue 6, 2010
Provisional PDF

Published 27 April 2010

\title{
Quality care in vesico-vaginal obstetric fistula: case series report from the regional hospital of Maroua-Cameroon
}

\section{Pierre Marie Tebeu ${ }^{1,2,3} \&$, Joseph Nelson Fomulu ${ }^{3}$, Achille Aurelien Mbassi', Jean Marie Tcheliebou', Anderson Sama Doh ${ }^{3}$, Charles Henry Rochat ${ }^{4}$}

${ }^{1}$ Ligue d'Initiative et de Recherche Active pour la Santé et l'Education de la Femme (LIRASEF), ${ }^{2}$ Department of obstetrics and Gynecology, Provincial hospital, Maroua, Cameroon, ${ }^{3}$ Department of obstetrics and Genecology, University hospitals, Yaoundé-Cameroon, ${ }^{4}$ Geneva Foundation for medical Education and Research (GFMER), Geneva, Switzerland

\section{\& Corresponding author}

Pierre Marie Tebeu, Department of Obstetrics and Gynecology, University Hospitals, Yaoundé- Cameroon, Tel: 00 (237) 77675533

\footnotetext{
Abstract

The World Health Organization (WHO) proposes a successful closure rate for first repair of vesico-vaginal obstetric fistula to be at $85 \%$ in each facility, with the continence achievement among the closed cases at $90 \%$. We are reporting the vesico-vaginal obstetric fistula outcome at the provincial hospital of MarouaCameroon from 2005 to August 2007. Among the overall 32 patients with vesico-vaginal fistula operated, 25 patients were at their first operation. The complete closure of vesico-vaginal fistula (VVF) was 23/25 $(92 \%)$ and among the 23 patients with complete closure $17(74 \%)$ had good continence. When we consider only the 25 patients who were at their first operation, the overall closure of VVF was 23/25 $(92 \%)$ and among them $17 / 23(74 \%)$ were continent. Large lesion, bladder neck lesions, vaginal adherence and rigid margin are associated with failure/incontinence. These factors must be taken into
} 
consideration when preparing patients for surgery or when assigning them to a surgeon within the surgical team.

\section{Background}

Some studies present the result of obstetric vesico-vaginal fistula (VVF) repair including repeating operations for the same patient [1]. Other studies present the result only as successful closure without taking into consideration the continence status [2]. WHO proposes the successful closure rate for first repair at $85 \%$ in each facility with the continence achievement among the closed cases at $90 \%$ [3]. In a recent study, we reported the risk factors for obstetric fistula in far North Cameroon [4], however, little is known about the treatment outcome. The objective of this study was to analyze the vesico-vaginal obstetric fistula outcome at the Regional Hospital of Maroua-Cameroon.

\section{Methods}

This was a case series study at the provincial hospital of Maroua-Cameroon from May 2005 to August 2007. The Maroua Provincial Hospital is a second level referral hospital for the Far North Province of Cameroon.

Women consulted in the Maroua provincial hospital for leakage of urine or stools through the vagina. The site and, size of fistulas were confirmed by speculum examination. Transurethral catheter was performed and followed by instillation of $1 \%$ methylen blue in the bladder to trace the leakage in small cases. During the study period we identified 48 patients with genital fistulae. We excluded the non obstetrical fistulas $(n=6)$; obstetrical recto-vaginal fistula $(n=3)$ as the study focused on vesico-vaginal fistulas; and obstetric VVF fistula treated by diversion $(n=7)$. Finally 32 obstetrical VVF were analyzed.

The Surgical technique included an infiltration with adrenaline serum, an incision in V/Y, a vésico-vaginal division and a suture without tension in two layers with monofilament and semi-resorbable thread. The $\mathrm{V} / \mathrm{C}$ incision was done for fistula localized on the uterine cervix.

Data were collected on the socio-economic status (age, marital status, educational level, occupation), reproductive history; circumstance of the occurrence of obstetric fistula; anatomic characteristics of the fistula and the treatment outcome. 
The data were collected in the standard file prepared for obstetric fistula patients. The information from the file was entered in the Excel software by an assistant nurse with good computer skills. Data was stored in the obstetric fistula database of the Department of Obstetrics and Gynecology of the Maroua provincial hospital. The data of this study was retrieved from the obstetric fistula database of the Department of Obstetrics and Gynecology in the provincial hospital of Maroua-Cameroon between May 2005 and August 2007.

Data analysis was performed using EPI Info 3.4. This descriptive analysis includes mean, median, range, standard deviation, $25 \%$ quartile (q1), 75\% quartile (q3), and proportions. The success rate was calculated as proportion of cure among treated patients. Characteristics from patients who were treated successfully were compared with patients with failure (i.e. not closed fistulas and residual incontinence).

\section{Results}

The mean age of the 32 patients at the time of intervention was 36.2 (SD: 14.3) years; 30(94\%) of women had no occupation; $7(22 \%)$ were divorced; $4(12.5 \%)$ were widows and $28(88 \%)$ had no formal education; $18(56.3 \%)$ patients did not have antenatal care during the indexed pregnancy; $27(84.4 \%)$ of patients had been in labor for more than 12 hours and $28(87.5 \%)$ pregnancies resulted in stillbirth (Table 1).

The patient's duration of stay with obstetric fistula ranged from 1 month to 33 years, with the median duration at 8.5 years. Among the 32 patients with obstetric VVF, 18 (56\%) were at bladder neck region, $26(81 \%)$ were more than $2 \mathrm{~cm}$ of size, and $22(68.8 \%)$ had vaginal adhesions (Table 2).

Among the overall 32 patients with vesico-vaginal fistula, closure was observed in $30(93.5 \%)$ patients. The complete closure with good continence was observed in 22 (73.3\%) of the 30 patients; closure with residual incontinence observed in $8(26.7 \%)$ of the 30 patients repaired and failure of closure was observed in 2 out of the 32 patients $(6.2 \%)$ patients.

Among the overall 32 patients with vesico-vaginal fistula operated, 25 patients were at their first operation. The complete closure of vesico-vaginal fistula was 23/25 (92\%) and among the 23 patients with complete closure $17(74 \%)$ had good continence. The continence procedure was performed for two patients with the transobturator technique (TOT), but only one of them had a good continence. 
We compared the overall 22 patients with closure and good continence mentioned above with the 10 patients with failure/incontinence. We found that patients with failure/incontinence have fistula more likely to be localized at the bladder neck region ( $80 \%$ vs. $50 \%$ ); with size more than $5 \mathrm{~cm}(30 \%$ vs. $9 \%$ ); with vaginal adherence ( $80 \%$ vs. $64 \%)$ and rigid edges ( $80 \%$ vs. $55 \%)$ (Table 3$)$.

\section{Discussion}

This study is the first according to our knowledge presenting the quality care in vesico-vaginal obstetric fistula according to the recent WHO recommendations. Among the 32 patients with VVF, the overall closure was observed in $30(93.5 \%)$ cases. Our result fit in the WHO target of $85 \%$ [3]. In the literature the overall closure range between $81-100 \%$ [5]. However, the overall closure does not necessary mean that the patient is cured, as $7-23 \%$ of the treated patients will have closure of their fistula, but still with a residual incontinence [5]. In the present report 8 out of the 32 patients (25\%) had closure, but still with residual incontinence. The continence procedure performed for two patients with TOT, but only one of them had a good continence. This minimally invasive operation should be further assessed so that it can demonstrate its effectiveness and probably become the "Gold standard". We suggest that the procedure should be evaluated in all fistula sites to improve their continence rate.

When we consider only the 25 patients who were at their first operation, the overall closure of VVF was $23 / 25(92 \%)$ and among them $17 / 23(74 \%)$ were continent. WHO recommends that $90 \%$ of the closed fistula should be also continent, and this implies the complete cure of the patient [3]. In the present study, 17 out of the 23 patients at their first attempt of repair were continent (74\%). The high rate of residual incontinence observed in this study could be due to the deteriorated anatomic presentation of our patients at surgery. Previous studies found that size of the fistula hole of more than $5 \mathrm{~cm}$, vaginal adherence and rigid margins were associated with poor surgical outcome [1]. The size of the sample is likely too small to determine differences between the groups with 'successful' outcomes versus those with failure/incontinence with any significance. We strongly recommend more studies with big sample for comparison between the two groups. Patient characteristics like parity and body stature are also of interest; however they are risk factors of obstetric fistula occurrence rather than those of quality care [6, 7]. 


\section{Conclusion}

Large lesion, bladder neck localization, vaginal adherence and rigid margin are associated with failure/incontinence. These factors must be taken into consideration when preparing patients for surgery or when assigning them to a surgeon within the surgical team.

\section{Competing interests}

There are no competing interests in relation to this manuscript.

\section{Author's contribution}

PMT: study concept, design, data collection, statistical analysis, manuscript writing, and review. JNF: manuscript writing and review. AAM: data collection. JMT: manuscript writing, and review. ASD: manuscript writing, and review. CHR: study concept, design, manuscript writing, and review.

\section{References}

1. Falandry L. Traitement des fistules uro-génitales postpartum en Afrique, 261 cas observés en dix ans. Prog Urol. 1992;2:861-73. This article on PubMed

2. Ramsey K, Iliyasu Z, Idoko L. Fistula Fortnight: innovative partnership brings mass treatment and public awareness towards ending obstetric fistula. Int J Gynaecol Obstet. 2007;99 Suppl 1:S130-

\section{This article on PubMed}

3. de Bernis L. Obstetric fistula: guiding principles for clinical management and programme development, a new WHO guideline. Int J Gynaecol Obstet. 2007;99 Suppl 1:S117-21. This article on PubMed

4. Tebeu PM, de BL, Doh AS, Rochat CH, Delvaux T. Risk factors for obstetric fistula in the Far North Province of Cameroon. Int J Gynaecol Obstet. 2009;107(1):12-5. This article on PubMed 
5. Muleta M. Obstetric fistula in developing countries: a review article. J Obstet Gynaecol Can. 2006;28(11):962-6. This article on PubMed

6. Holme A, Breen M, MacArthur C. Obstetric fistulae: a study of women managed at the Monze Mission Hospital, Zambia. BJ OG. 2007;114(8):1010-17. This article on PubMed

7. Rahman MS, Al Suleiman SA, El Yahia AR, Rahman J. Surgical treatment of rectovaginal fistula of obstetric origin: a review of 15 years experience in a teaching hospital. J Obstet Gynaecol. 2003;23(6):607-10. This article on PubMed

Table 1: Clinical manifestations in patients with the obstetric fistula

Page number not for citation purposes 6 


\begin{tabular}{|c|c|c|}
\hline \multirow[t]{2}{*}{ Characteristics } & \multicolumn{2}{|c|}{$\begin{array}{l}\text { Frequency among vesico vaginal } \\
\text { fistula cases }(\mathrm{N}=32)\end{array}$} \\
\hline & $\mathbf{n}$ & $\%$ \\
\hline \multicolumn{3}{|l|}{ Vulva irritability } \\
\hline No & 22 & 68.8 \\
\hline Yes & 10 & 31.2 \\
\hline \multicolumn{3}{|l|}{ Vaginal itching } \\
\hline No & 31 & 96.9 \\
\hline Yes & 1 & 3.1 \\
\hline \multicolumn{3}{|l|}{ Dysuria } \\
\hline No & 29 & 90.6 \\
\hline Yes & 3 & 9.4 \\
\hline \multicolumn{3}{|c|}{ Difficulties of walking } \\
\hline No & 29 & 90.6 \\
\hline Yes & 3 & 9.4 \\
\hline \multicolumn{3}{|l|}{ Urine lose } \\
\hline No & 0 & 0 \\
\hline Yes & 32 & 100.0 \\
\hline \multicolumn{3}{|c|}{ Vulvar Dermatitis } \\
\hline No & 15 & 46.9 \\
\hline Yes & 17 & 53.1 \\
\hline \multicolumn{3}{|l|}{ Height } \\
\hline $147-149$ & 2 & 6.2 \\
\hline $150-167$ & 15 & 46.9 \\
\hline unknown & 15 & 46.9 \\
\hline \multicolumn{3}{|l|}{ Leucorrhoea } \\
\hline No & 30 & 93.8 \\
\hline Yes & 2 & $6 . .2$ \\
\hline \multicolumn{3}{|c|}{ Inflammatory cervix } \\
\hline No & 27 & 84.3 \\
\hline Yes & 2 & 6.3 \\
\hline Not seen & 3 & 9.4 \\
\hline
\end{tabular}

Median duration of obstetric fistula was 8.5 years (Q1=0.8yrs; Q3 $=20.5 \mathrm{yrs}$ ) 
Table 2: Characteristics of fistula lesion

\section{Vesico-vaginal fistula $(\mathrm{N}=32)$}

n

$\%$

\section{Characteristics}

\section{Fistula palpable}

No

Yes

Soft

Rigid

Localization

Bladder

Trigonal

Cervical

Urethral

Fistula size

$<2 \mathrm{~cm}$

$2-5 \mathrm{~cm}$

$>5 \mathrm{~cm}$

Vaginal adherence

No

Yes

Surgical approach

Vaginal

Abdominal

Combined

Complementary maneuver at surgery

None

Martius

Epiloon interposition

Re-implantation

Duration (in minutes) of operation, median(percentile 25 and 75)

Duration (in days)of bladder draining, median(percentile 25 and 75)

\section{Surgical outcome}

Close and continent

Close but not continent

Complete failure
0

32

12

20

0

100.0

37.5

62.5

15.6

28.1

31.3

25.0

$8 \quad 25.0$

$6 \quad 18.8$

$\begin{array}{ll}61 & 65.7\end{array}$

$5 \quad 15.5$

$10 \quad 31.2$

$22 \quad 68.8$

$27 \quad 84.4$

$2 \quad 6.3$

$3 \quad 9.4$

$\begin{array}{cc}5 & 15.6 \\ 24 & 75.0 \\ 1 & 3.1 \\ 2 & 6.3\end{array}$

$145(115 ; 195)$

$12(11 ; 14)$

75.0

3.1

6.3

$\mathrm{n}=$ number of cases; $\%=$ percentage 
Table 3: Comparison of the patients with closure and continence and those with failure/incontinence

\begin{tabular}{|c|c|c|c|c|}
\hline \multirow[t]{3}{*}{ Characteristics } & \multicolumn{4}{|c|}{ Obstetric fistula } \\
\hline & \multicolumn{2}{|c|}{ Success $(\mathbf{N}=22)$} & \multicolumn{2}{|c|}{ Failure/ incontinence $(\mathrm{N}=10)$} \\
\hline & $\mathbf{n}$ & $(\%)$ & $\mathbf{n}$ & $(\%)$ \\
\hline \multicolumn{5}{|l|}{ Edges } \\
\hline Soft & 10 & 45.5 & 2 & 20.0 \\
\hline Rigid & 12 & 54,5 & 8 & 80.0 \\
\hline \multicolumn{5}{|l|}{ Localization } \\
\hline Bladder/trigon & 11 & 50.0 & 2 & 20.0 \\
\hline Cervico-urethral & 11 & 50.0 & 8 & 80.0 \\
\hline \multicolumn{5}{|l|}{ Fistula size } \\
\hline$=<5 \mathrm{~cm}$ & 20 & 90.9 & 7 & 70.0 \\
\hline $6-10$ & 2 & 9.1 & 3 & 30.0 \\
\hline \multicolumn{5}{|l|}{ Vaginal adherence } \\
\hline No & 8 & 36.4 & 2 & 20.0 \\
\hline Yes & 14 & 63.6 & 8 & 80.0 \\
\hline
\end{tabular}

